\title{
Drivers of autochthonous and imported malaria in Spain and their relationship with meteorological variables
}

\author{
Arturo Sousa $^{1}\left[\right.$ ] $\cdot$ Mónica Aguilar-Alba ${ }^{2} \cdot$ Mark Vetter $^{3} \cdot$ Leoncio García-Barrón $^{4} \cdot$ Julia Morales $^{1}$
}

Received: 15 October 2020 / Accepted: 28 January 2021

(c) Springer Nature Switzerland AG 2021

\begin{abstract}
Since the early twentieth century, the intensity of malaria transmission has decreased sharply worldwide, although it is still an infectious disease with a yearly estimate of 228 million cases. The aim of this study was to expand our knowledge on the main drivers of malaria in Spain. In the case of autochthonous malaria, these drivers were linked to socioeconomic and hygienic and sanitary conditions, especially in rural areas due to their close proximity to the wetlands that provide an important habitat for anopheline reproduction. In the case of imported malaria, the main drivers were associated with urban areas, a high population density and international communication nodes (e.g. airports). Another relevant aspect is that the major epidemic episodes of the twentieth century were strongly influenced by war and military conflicts and overcrowding of the healthcare system due to the temporal overlap with the pandemic flu of 1918. Therefore, military conflicts and overlap with other epidemics or pandemics are considered to be drivers of malaria that can - in a temporary manner - exponentially intensify transmission of the disease. Climatic factors did not play a relevant role as drivers of malaria in Spain (at least directly). However, they did influence the seasonality of the disease and, during the epidemic outbreak of 1940-1944, the climate conditions favored or coadjuvated its spread. The results of this study provide additional knowledge on the seasonal and interannual variability of malaria that can help to develop and implement health risk control measures.
\end{abstract}

Keywords Drivers of malaria $\cdot$ Wetlands $\cdot$ Imported malaria $\cdot$ Autochthonous malaria $\cdot$ Mediterranean climate $\cdot$ Thermal variables

Communicated by Katerina Pantavou, Guest Editor and Georgios K. Nikolopoulos, Chief Editor.

Topical Collection: Health Risks from Infectious Diseases in a Changing Mediterranean Environment.

Arturo Sousa
asousa@us.es
Mónica Aguilar-Alba
malba@us.es
Mark Vetter
mark.vetter@ fhws.de
Leoncio García-Barrón
leoncio@us.es
Julia Morales
jmorales@us.es
Department of Plant Biology and Ecology, Universidad de
Sevilla, 41012 Seville, Spain
Department of Physical Geography and AGR, Universidad de
Sevilla, 41004 Seville, Spain
Geovisualization, Würzburg University of Applied Sciences,
Würbburg, Germany
Department of Applied Physics II, Universidad de Sevilla,
41012 Seville, Spain

\section{Introduction}

Since the early twentieth century, the reach and especially the intensity of malaria transmission have decreased considerably (Zhao et al. 2016). The estimated number of cases worldwide was 251 million in 2010, 231 million in 2017, and 228 million in 2018, mostly concentrated in Africa (93\%; World Health Organization [WHO] 2019). However, despite the advances of the last decades, malaria is still a major health problem, highlighting the need to increase investment in measures for its eradication and prevention. For example, although the situation is improving, progress is slow, with 585,000 deaths from malaria in 2010, 416,000 in 2017, and 405,000 in 2018 (WHO 2019). This situation may worsen in endemic countries in present and future years. The coronavirus disease (COVID-19) pandemic caused by SARS-CoV-2 has placed an additional load on already overloaded healthcare services, aggrevated by scarce resources, which fight to control other diseases, such as tuberculosis 
and human immunodeficiency virus (Chanda-Kapata et al. 2020).

In Europe, indicators related to socioeconomic improvement (wealth, life expectancy, degree of urbanization) are strongly associated with the observed decrease in malaria. At the same time, indicators that describe the climatic conditions and changes in the uses of soil have shown weaker correlations (Zhao et al. 2016). In the specific case of Spain, autochthonous malaria was declared to have been officially eradicated by WHO in 1964 (Pletsch 1965; Díaz et al. 2005), with the last case of death recorded in 1959 and the last 24 cases of infection recorded in 1961 (Sousa et al. 2009). However, there have been cases associated with imported malaria from 1962 onwards (Navarro 2002), with a clear progressive increase up to the present time that began in the mid-1970s.

The different types of malaria can be categorized according to the origin of the vectors of the genus Anopheles, which transmit the protozoa of the genus Plasmodium that cause malaria. From a quantitative perspective, the most frequent types of malaria are indigenous, or autochthonous malaria, and imported malaria (Sousa et al. 2020). In the case of autochthonous malaria, the disease is acquired from the bite of an infected mosquito in a country where malaria is present, while imported malaria refers to malaria in patients who acquire the disease in endemic countries and who are diagnosed or start to show symptoms in countries where the disease has been eradicated (Díaz et al. 2005; López-Vélez and Molina 2005). Currently, the only vector capable of transmitting the disease in a significant manner in Spain is Anopheles atroparvus, which is widely distributed throughout the country (Díaz et al. 2005; Iriso et al. 2017). However, there is another vector related to malaria in Spain, namely Anopheles labranchiae; this species disappeared from southeastern Spain in 1973 but can still be found in northern Africa (Díaz et al. 2005; Blázquez and De Zulueta 1980; Iriso et al. 2017).

An improvement in socioeconomic conditions and, consequently, in hygienic and sanitary conditions, is one of the key factors in the eradication of malaria worldwide. It is notable that countries which have managed to eradicate malaria show socioeconomic indicators equivalent to those of European countries that have eradicated this disease (Zhao et al. 2016). It is much more complex to establish the role of other factors linked to human activity and, especially, the importance of climatic factors as drivers of the disease. Some studies have analyzed the possibility of potential changes in the transmission of malaria due to the effect of climate change on the distribution of anophelines in Europe and the Mediterranean region (Hertig 2019). However, it is important to consider that the influence of temperature on the development of malaria does not seem to be linear (Smith et al. 2014). Therefore, if variations in temperature are close to the higher limit of the vector and pathogen, the transmission may even tend to decrease. On the contrary, if the variations in daily temperature are not close to the minimum limit, the transmission may increase, thus also increasing the morbidity of the disease (Smith et al. 2014). Consequently, in order to understand the effect of the climatic variables as drivers of malaria, it is necessary to study, as completely as possible, historical trends and historical epidemic outbreaks of the disease. Several authors have pointed out the importance of better explorations of the spatio-temporal drivers of malaria in Europe, improving knowledge on this topic through historical epidemiology (Zhao et al. 2016).

The main objective of this study was to analyze the main drivers of the eradication of autochthonous malaria in Spain through an analysis of the decrease of the disease and its spatial distribution during the twentieth century. We explored whether its eradication was a constant and homogeneous process or whether it was affected by epidemic episodes influenced by different drivers. Separately, we also analyzed the evolution of imported malaria and its spatial distribution during the twentieth century, with the aim of determining whether it was influenced by the same drivers as autochthonous malaria. Once the main non-climate drivers had been analyzed, we explored the seasonality of malaria and the interannual influence of the climatic variables. This analysis allowed us to identify whether climatic factors are essential drivers of the intra- and interannual variability of malaria or whether they have little or no relevance.

\section{Material and methods}

The aim of this study included examining cases of autochthonous and imported malaria; therefore, different information sources related to both types of malaria were used. Table 1 presents a general description of the data sources used to obtain the results of the different sections, along with the spatial and temporal scale of the available or used data.

\section{Trends of autochthonous malaria during the twentieth century}

Historical archives were searched for available records of the number of people who were infected with and who died from autochthonous malaria in Spain during the twentieth century. Registration of the number of people who died from malaria began in 1900, although registration of the number of infected people was first centralized only in 1943 (Navarro 2002). The main source of data used in this study was the historical archives of the annual reports of the Spanish Statistics Institute (SSIbase 2020), which have been used for similar purposes in previous studies on malaria (Rico-Avelló 1950; Fernández Astasio 2003; Rodríguez-Ocaña et al. 2003; Sousa et al. 2009, 2014) and 
Table 1 General synthesis of the data sources used in this study

\begin{tabular}{|c|c|c|c|c|}
\hline Results & Data reported & Source & Spatial extension & Temporal period (years) ${ }^{\mathrm{a}}$ \\
\hline \multirow[t]{8}{*}{ Autochthonous malaria } & $\begin{array}{l}\text { Number of deaths due to malaria } \\
\text { with respect to the total annual } \\
\text { number of deaths }\end{array}$ & $\begin{array}{l}\text { Database of the Spanish Statis- } \\
\text { tics Institute }\end{array}$ & Spain & $1900-1965$ \\
\hline & $\begin{array}{l}\text { Annual rate of mortality decrease } \\
\text { and cumulative annual rate of } \\
\text { mortality decrease }\end{array}$ & $\begin{array}{l}\text { Database of the Spanish Statis- } \\
\text { tics Institute }\end{array}$ & Spain & 1900-1959 \\
\hline & $\begin{array}{l}\text { Spatial distribution of the num- } \\
\text { ber of infected people }\end{array}$ & $\begin{array}{l}\text { Database of the Spanish Statis- } \\
\text { tics Institute }\end{array}$ & Spain (provincial) & 1949 \\
\hline & $\begin{array}{l}\text { Distribution of the number of } \\
\text { infected people with respect to } \\
\text { the size of the population }\end{array}$ & $\begin{array}{l}\text { Database of the Spanish Statis- } \\
\text { tics Institute }\end{array}$ & Spain & 1955-1959 \\
\hline & $\begin{array}{l}\text { Monthly distribution of the num- } \\
\text { ber of infected people }\end{array}$ & $\begin{array}{l}\text { Database of the Spanish Statis- } \\
\text { tics Institute }\end{array}$ & Spain & 1949 and $1954-1956$ \\
\hline & $\begin{array}{l}\text { Relationship between the mean } \\
\text { monthly temperature and the } \\
\text { total number of infected people }\end{array}$ & $\begin{array}{l}\text { Database of the Spanish Statis- } \\
\text { tics Institute } \\
\text { Meteorological Observatory of } \\
\text { Huelva (AEMET) }\end{array}$ & Spain (Huelva) & $1949,1954-1957$ \\
\hline & $\begin{array}{l}\text { Number of patients attended to } \\
\text { or registered in the antimalarial } \\
\text { dispensaries }\end{array}$ & $\begin{array}{l}\text { Database of the Spanish Statis- } \\
\text { tics Institute }\end{array}$ & Spain (regional) & 1931-1949 \\
\hline & $\begin{array}{l}\text { Relationship between the number } \\
\text { of patients attended to or } \\
\text { registered in the antimalarial } \\
\text { dispensaries and meteorologi- } \\
\text { cal variables }\end{array}$ & $\begin{array}{l}\text { Database of the Spanish Statis- } \\
\text { tics Institute } \\
\text { Global Climate Monitor }\end{array}$ & Spain (regional) & 1931-1932 and 1936-1949 \\
\hline Other infectious diseases & $\begin{array}{l}\text { Number of deaths due to tuber- } \\
\text { culosis, meningitis, influenza, } \\
\text { measles, diphtheria, smallpox, } \\
\text { scarlet fever, syphilis, and } \\
\text { typhus }\end{array}$ & $\begin{array}{l}\text { Database of the Spanish Statis- } \\
\text { tics Institute } \\
\text { Navarro (2002) }\end{array}$ & Spain & $1910-1945$ \\
\hline \multirow[t]{4}{*}{ Imported malaria } & $\begin{array}{l}\text { Cumulative rate of annual } \\
\text { increase of the number of } \\
\text { infected people }\end{array}$ & $\begin{array}{l}\text { Bulletins of the Instituto Carlos } \\
\text { III } \\
\text { Spanish Network of Epidemio- } \\
\text { logical Surveillance } \\
\text { Sistema Básico de Vigilancia } \\
\text { Comunitat Valenciana (Basic } \\
\text { Surveillance System of the } \\
\text { Comunitat Valenciana) }\end{array}$ & Spain & $1975-2018$ \\
\hline & $\begin{array}{l}\text { Spatial distribution of the num- } \\
\text { ber of infected people }\end{array}$ & Bulletins del Instituto Carlos III & Spain (regional) & 2010-2018 \\
\hline & $\begin{array}{l}\text { Monthly distribution of the num- } \\
\text { ber of infected people }\end{array}$ & $\begin{array}{l}\text { Spanish Network of Epidemio- } \\
\text { logical Surveillance }\end{array}$ & Spain & 2010-2016 and 2018 \\
\hline & $\begin{array}{l}\text { Relationship between the mean } \\
\text { monthly temperature and the } \\
\text { total number of infected people }\end{array}$ & $\begin{array}{l}\text { Spanish Network of Epidemio- } \\
\text { logical Surveillance } \\
\text { Meteorological Observatory of } \\
\text { Madrid [European Climate } \\
\text { Assessment and Dataset } \\
\text { (ECA\&D)] }\end{array}$ & Spain (Madrid) & 2010-2018 \\
\hline \multirow[t]{2}{*}{ Current climate trends } & $\begin{array}{l}\text { Analysis of quintiles of the mean } \\
\text { annual temperature }\end{array}$ & Global Climate Monitor & Spain (regional) & 1931-1949 \\
\hline & $\begin{array}{l}\text { Analysis of quintiles of the } \\
\text { annual precipitation }\end{array}$ & Global Climate Monitor & Spain (regional) & 1931-1949 \\
\hline
\end{tabular}

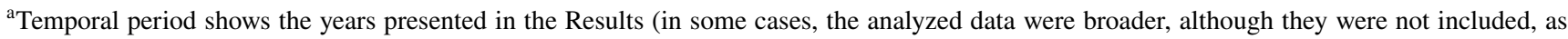
they presented some methodological limitations) 
other infectious diseases that had to be recorded (Navarro 2002; Navarro et al. 2012; Chowell et al. 2014). We collected data on the number of people infected and deceased, areas of malaria with unhealthy water bodies, the number of antimalarial dispensaries (cases recorded and/or attended to in these centers), and the provincial distribution of infected people per population size (see Table 1). One of the limitations of this historical database is that the most detailed records, which correspond to a provincial scale, only appear for the periods of 1916-1930 (deceased) and 1949 and 1954-1961 (infected). Data on unhealthy bodies of water refer to floodplains that require sanitation measures because they are suitable for the reproduction of the vector that transmits malaria. These data were collected from the Directorate General of Agriculture in 1913 and 1916 and exclude foci of ricefields, hemp rafts, riverbanks, channeled streams, gutters, and railroad trenches (Sousa et al. 2014).

In order to better analyze the main drivers of the eradication of autochthonous malaria in Spain during the twentieth century, we studied the decrease in the number of cases of malaria. To this end, we first calculated the number of people deceased due to malaria with respect to the total number of annual deaths in Spain. More specifically, we calculated the quotient of the annual number of deaths by malaria $\left(M_{n}\right)$ per one thousand deaths in the same year $(n)$, including all causes of death $\left(D_{n}\right)$. Equation 1 represents the quotient between these two variables:

$I_{n}=M_{n} / 1000 D_{n}$.

Second, we calculated the interannual decrease of the number of deaths by autochthonous malaria with respect to the total number of deaths. More specifically, we calculated the difference in the number of deaths due to autochthonous malaria between consecutive years with respect to the total number of deaths, expressed in thousands, during the complete period of 1901 to 1959 (Eq. 2):

$\delta_{n}=\left(M_{n}-M_{n-1}\right) / 1000 M_{\mathrm{T}}$,

where $M_{\mathrm{T}}$ is the total number of deaths due to malaria throughout the entire period analyzed. The total cumulative decrease was calculated as the sum of the deviations of the reference year $n$ with all the preceding deviations (Eq. 3):

$A_{n}=\left(\sum \delta_{i}\right) \quad$ for $i=1,2, \ldots n ; n \leq N$,

where $A_{n}$ represents the cumulative increase of deaths in year $n$ per every 1000 deaths for the entire period analyzed. In all cases, the polynomial and/or linear regression lines related to the people who died of autochthonous malaria were calculated.
From the data of the SSIbase archive, we gathered the distribution of infected people by provincal capitals with respect to the total number of cases of malaria reported in the country (period of 1950-1959). From 1955 onwards, the information recorded in these archives was broader and included the distribution of infected people according to the size of the population centers (province capitals, centers of $>20,000$ inhabitants and centers of $\leq 20,000$ inhabitants).

We also compared the evolution of mortality due to malaria with the main infectious diseases in Spain during the period of 1900-1959. The data were collected from the national records of Spain stored in SSIbase by the Spanish Epidemiological Centre of the Carlos III Health Institute (Navarro 2002) between 1910 and 1945 (Table 1). This data source was also used to calculate the annual evolution of the Spanish population from 1900 to 1965 . The data on population density in the provinces and regional area occupied by greenhouse crops in 2019 were obtained from the Spanish Statistics Institute (https://www.ine.es/jaxiT3/ Datos.htm?t=2852\#!tabs-tabla) and the Spanish Ministry of Agriculture, Fisheries and Food (https://www.mapa.gob. es/es/estadistica/temas/estadisticas-agrarias/agricultura/ esyrce/), respectively.

\section{Trends of imported malaria during the twentieth and twenty-first centuries}

Data on imported malaria in Spain started to be recorded in the early 1970s. However, given that some of these data are uncertain, the calculation for this study was based on the number of cases recorded in the period of 1975-2018. These data were obtained from the Spanish epidemiological surveillance systems (SSIbase 2020), the Bulletins of the Carlos III Institute (2020), the Spanish Network of Epidemiological Surveillance (2020), and the Basic Surveillance System of the Valencian Community (2020). Herrador et al. (2019) and Sousa et al. (2020) have provided a good synthesis of these data sources, their online localization and their limitations.

Unlike autochthonous malaria, for cases of imported malaria, there is a stable and constant record of both infected and deceased people. The number of recorded cases of people who died of imported malaria is very small and has changed very little over time. For example, in the entire country there were five recorded deaths from imported malaria in 1975 and a total of eight cases of death in 1995 (Navarro 2002). Therefore, we calculated the interannual increase in imported malaria, during the twentieth and twenty-first centuries, as the difference in the number of cases recorded every year $n$ with respect to the the number recorded previous year $(n-1)$. This was then represented as the annual cumulative increase in the number of cases of imported malaria, from the sum of the deviations of reference year $n$ with all the previous deviations. We 
also calculated the linear and polynomial regression lines of imported malaria patients in Spain for the period analyzed. These equations allowed us to project the trends in the increase of cases, whenever the conditions were the same as the current conditions, up to the year 2050 .

The regional distribution of imported malaria in Spain was mapped using the data available in the Bulletins of the Carlos III Institute for the period of 2010-2018. The monthly evolution of the cases of imported malaria was investigated using the data provided by the Spanish Network of Epidemiological Surveillance for the periods of 2010-2016 and 2018 (there are no available records for 2017).

To map the provincial distribution of autochthonous malaria and the regional distribution of imported malaria, we used Geographical Information System (GIS) data. Different studies have used GIS tools to analyze the morbidity and/or mortality of malaria at the regional, national or global scale, as well as the main drivers of the disease (Hay et al. 2002; Omumbo et al. 2002; Sipe and Dale 2003; Guerra et al. 2006; Sousa et al. 2014, 2019, 2020; Gwitira et al. 2019; Battle et al. 2019; Weiss et al. 2019). In our case, we used these tools - from the data of the years available in SSIBase - to generate the mapping of the total number of people who died of autochthonous malaria in Spain (year 1949) and the total number of people infected with imported malaria (2010-2018). In these maps, we used the cartographic choropleth display method (Schiewe 2019). The maps were also used to represent data on the provincial population density and the area occupied by intensive greenhouse crops in the different Spanish regions. The electronic supplementary material (ESM) includes the names of the autonomous communities or regions (see ESM Fig. S1) and the provinces that include these regions (see ESM Fig. S2), with the aim of making it easier for the reader to locate them on the maps presented in this study.

\section{Data and methodology related to the climate variables}

The influence of meteorological variables on the morbidity of malaria was analyzed intra- and interannually. For the interannual analysis, we selected the Meteorological Observatory of Huelva (AEMET, Spanish Meteorological Office) as representative of one of the most endemic areas of the entire country. We used the data of the mean, minimum and maximum monthly temperatures and compared these with the relative monthly morbidity of autochthonous malaria (monthly proportion with respect to the total annual morbidity) for the periods of 1949 and 1954-1957. This relative rate allows the data of different years with a very different number of infected people to be compared. An equivalent analysis was conducted with the monthly data of imported malaria for the period of 2010-2018. In the case of imported malaria, we used data from the meteorological observatory of Madrid, the largest urban population center of the country, due to its large number of infected people and its central geographic position. These data were treated in the same way as the monthly data of autochthonous malaria, with the aim of comparing the intraannual evolution of both types of malaria with respect to the mean monthly temperatures.

For the interannual analysis, we studied the correlation between the main meteorological variables (spring precipitation, summer precipitation, mean monthly precipitation of spring and mean summer temperature) and the number of infected people attended to or recorded in the antimalarial dispensaries for the periods of 1931-1932 and 1936-1949 in the regions that were most affected by autochthonous malaria (Extremadura, Western Andalusia and Murcia). Given that the meteorological series present several gaps in this period, we used the data obtained from the Global Climate Monitor (GCM). This database provides a world historic series of monthly precipitation and temperature from January 1901 to December 2016 (https://www.globalclim atemonitor.org/). Moreover, GCM allows data in cells of $0.5^{\circ} \times 0.5^{\circ}$ latitude-longitude to be downloaded (CamarilloNaranjo et al. 2019), which generates a spatial resolution that enables the detection of regional climate differences. GCM was also used to climatically classify the years with available data on the number of infected people recorded in the antimalarial dispensaries (1931-1949), using 1901-1950 as the reference period. For each of the three regions with a greater number of infected people, based on the distribution of quintiles, the years were classified according to climate as very dry, dry, normal, wet and very wet years (annual precipitation) and as very cold, cold, normal, warm and very warm years (mean annual temperature).

\section{Results and discussion}

\section{Drivers of autochthonous malaria during the twentieth century}

The proportion of the total number of deaths due to autochthonous malaria, in parts per thousand, together with the evolution of the Spanish population are shown in Fig. 1.

From the early twentieth century onwards, there was a sharp decrease in the number of deaths due to malaria, which progressively became less pronounced with the creation of the Central Anti-Malaria Commission in 1924, until the definitive eradication of autochthonous malaria in Spain. The last death due to malaria was recorded in 1959 and the last cases of infection were recorded in 1961 (Díaz et al. 2005). Throughout this period, there were episodes of epidemic peaks of malaria, with two major peaks in 1917-1922 and 1940-1944, respectively (Fig. 1). The first epidemic 


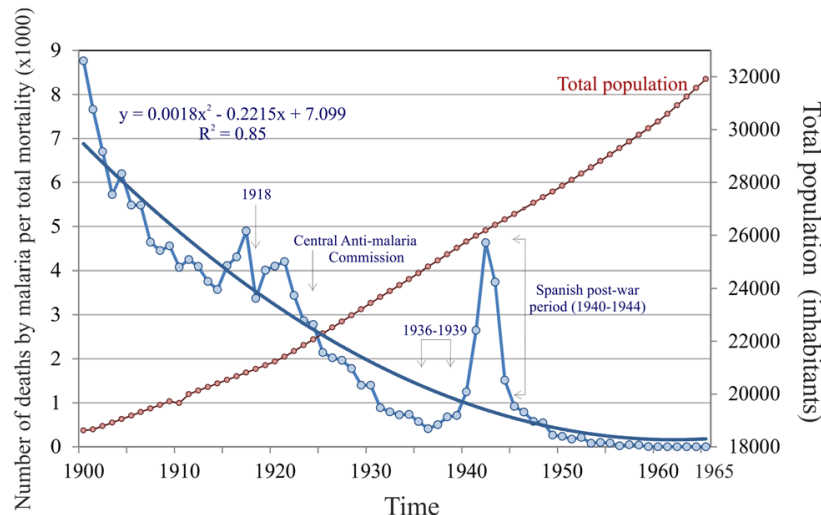

Fig. 1 Number of deaths due to malaria in Spain with respect to the total annual mortality $(\times 1000)$ and population growth for the period of 1900-1965 and the polynomial function that it fits to

peak reached its zenith in 1918 (2347 deaths), but the decreasing trend recovered thereafter to the levels recorded before 1914 (1609 deaths) in 1922 (1518 deaths). This epidemic episode presents a relative decrease in 1918-1919 due to the increase in total mortality caused by the wrongly called "Spanish Influenza" pandemic (Chowell et al. 2014). In 1918, the total number of deaths caused by this virus was estimated to be at least 147,114 people (Trilla et al. 2008), although other authors report it as causing 230,036 deaths and highlight the coincidence of the mortality peaks of the 1918 influenza pandemic with an outbreak of malaria (Sousa et al. 2020).

There was a second peak of malaria cases between 1940 and 1944 after the end of the Spanish Civil War (1936-1939), which preceded the Second World War (1939-1945); during this period, the maximum number of deaths due to malaria was reached in 1942 (1781 deaths). The main drivers of this outbreak are linked to population displacements, hunger, the scarcity of antimalarial drugs, and the proliferation of anopheles due to the abandonment of antimalarial campaigns (Rico-Avelló 1950; RodríguezOcaña et al. 2003; Barona and Perdiguero-Gil 2008; Sousa et al. 2014). More recent studies have analyzed, separately, the spatial evolution of this epidemic peak in the different Spanish regions, with the authors concluding that the movements of both citizens and troops after the war conflict, along with the overcrowding and/or detention of population sectors in forced labor camps, contributed to intensifying this outbreak (Sousa et al. 2020). From 1947, Spain recovered to the pre-Spanish Civil War levels of 1935.

To better understand which factors act as drivers of malaria, we compared how the main infectious diseases evolved in Spain from 1910 to 1945. Regarding the epidemic peak of 1917-1922, in addition to the already mentioned partial coincidence with the 1918-1919 influenza pandemic, there were outbreaks of meningitis and tuberculosis. During the epidemic peak of 1940-1944, there were also outbreaks of syphilis and typhus. On the other hand, no statistically significant correlation was found for the period of 1910-1945 between malaria and these infectious diseases. However, after removing the two epidemic peaks of malaria from the temporal analysis, we obtained a high correlation $\left(R^{2}=0.81\right)$ between malaria and typhus, and between malaria and syphilis $\left(R^{2}=0.82\right)$, from 1920 to 1937 , suggesting that there are common hygienic/sanitary and socio-economic drivers between these three infectious diseases. In this context, it is widely known that typhus and syphilis epidemics are historically related to war conflicts and that overcrowding is associated with the latter (Goldmeier and Guallar 2003; Raoult et al. 2004; Tampa et al. 2014).

To better understand the inflection points of these epidemic episodes, we calculated the rate of decrease of autochthonous malaria. Figure 2 shows the interannual decrease in the number of deaths due to malaria (Fig. 2a) and its cumulative decrease (Fig. 2b). This rate of decrease was calculated as the difference in the number of deaths, between consecutive years, with respect to the total mortality - expressed in thousands-for the complete period of 1901 to 1959. The sections above the polynomial function indicate periods in which the mortality due to malaria began to decrease, while the sections below the polynomial function (negative values in Fig. 2a) indicate periods in which the situation did not improve or even worsened. In this latter case, the annual rate of decrease in deaths by malaria is close to zero or even negative; that is, the number of deaths increases with respect to the previous year.

This analysis allows the effect of the Antimalarial Commission during the period of 1924-1936 (Fig. 2a), when the lowest mortality was achieved (only 170 deaths in 1936), to be clearly appreciated. However, with the beginning of the Spanish Civil War in July 1936, the number of deaths began to rise again, increasing more rapidly during the period of 1940-1944 once the war was over. The annual decrease in the rate of deaths due to malaria became negative again between 1940 and 1942 (Fig. 2a); then, in 1943, it turned positive again due to the beginning of an improvement process associated with the development and expansion of the antimalarial dispensaries (Rico-Avelló 1950; Rodríguez-Ocaña et al. 2003; Sousa et al. 2020), whose number increased from 187 in 1942 to 322 in 1946. In fact, the analysis of the relationship between the number of dispensaries and the number of malaria patients treated, only during the period of 1936-1943, displays a very high correlation $\left(R^{2}=0.96\right)$. This correlation clearly links the decrease in the prevalence of the disease to the improvement in the hygienic/sanitary conditions, without excluding an improvement in the general socioeconomic conditions throughout the country. 


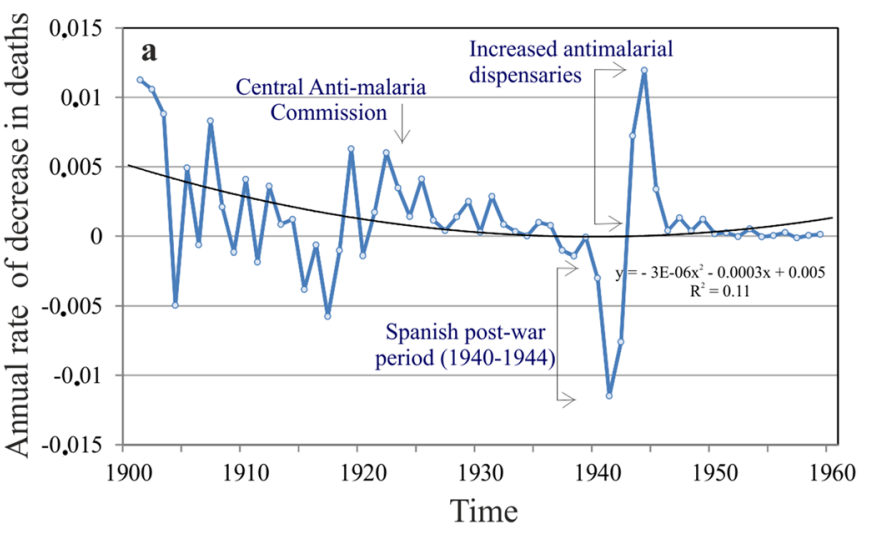

Fig. 2 a Annual rate of decrease in the number of deaths due to malaria in Spain (1900-1951) and its polynomial function. b Cumulative annual rate of deaths due to malaria in Spain (1900-1951) and

Up to this point, the results show that, from 1940 onwards, a general deterioration in hygienic/sanitary conditions associated with the war conflict disrupted the malaria eradication process in Spain, which had been initiated in the early twentieth century. Therefore, it is worth exploring how these extraordinary conditions contributed to delaying the eradication of the disease. To answer this question, we represented the rate of decrease in its cumulative form (Fig. 2b). The fit of the polynomial function (continuous line) is $R^{2}=0.85$; however, if we remove the values of the epidemic peak of 1940-1944, the fit of the function improves to $R^{2}=0.93$ (Fig. 2b). Using the same data and removing the period of 1940-1944, we note that the eradication of autochthonous malaria in Spain could have been advanced to 1951 (provided that Spain had continued the national malaria eradication programs that were being carried out before 1936). Therefore, irrespective of other contemporary historical factors, the military conflict may have resulted in an estimated delay of 8-12 years in the eradication of autochthonous malaria in Spain with respect to other European countries, such as Austria and Finland (1947) or Germany and France (1950) (Petersen et al. 2013). Specifically, after the end of the Spanish Civil War conflict (1936-1939), the antimalarial fight slowed down as a consequence of the socioeconomic situation, deterioration of the national hygienic/ sanitary system, and the international isolation of Spain (Rico-Avelló 1950; Rodríguez-Ocaña et al. 2003). Therefore, it seems reasonable to suggest that military conflicts could be the main barrier to the eradication of malaria in other countries of Africa, Asia and the Americas where malaria is still endemic and there are ongoing military conflicts.

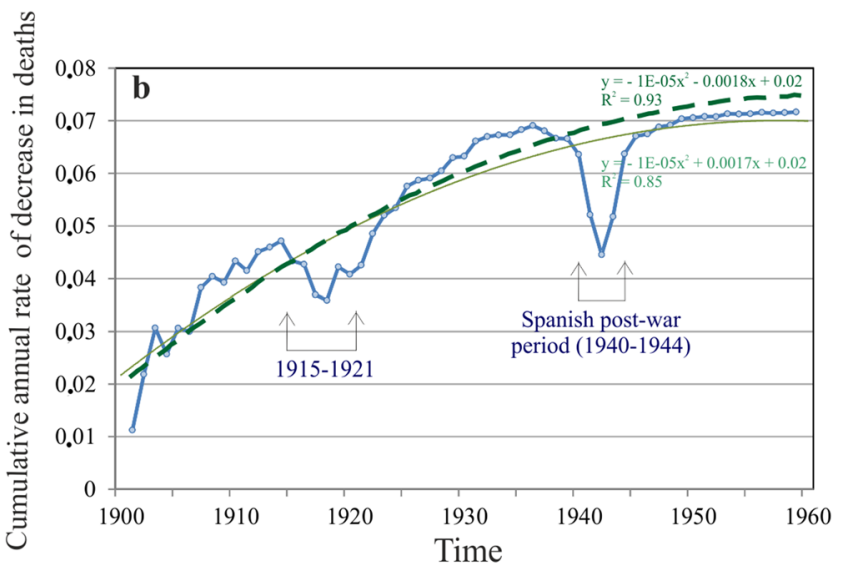

its polynomial function (light-green continuous line). The dark-green dashed line represents the polynomial function after removal of the epidemic peak of the Spanish post-war period

\section{Drivers of imported malaria during the twentieth and twenty-first centuries}

The data gathered in the first Spanish report on the epidemiological surveillance of transmittable diseases in 2016 highlight that $95 \%$ of the imported cases of malaria came from Africa, especially from Equatorial Guinea, Mali, Nigeria, and Senegal, among other countries (Spanish Network of Epidemiological Surveillance 2020). The most frequent profile of an infected person was that of a male $(68 \%)$ within the age range of 25-54 years. The causes of traveling to the endemic regions would be linked to visits to relatives and friends, and, to a much lower extent, to migration, tourism, and business trips. These results are in agreement with studies conducted in the scope of the Community of Madrid (Rey et al. 2010).

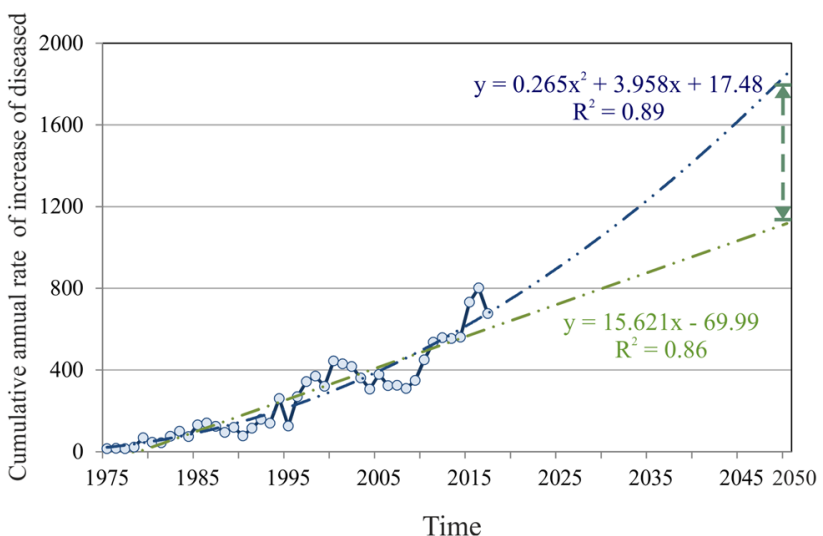

Fig. 3 Cumulative annual rate of increase in the number of people infected with imported malaria in Spain from 1975 to 2018 and its linear (green dashed line) and polynomial (blue dashed line) regression lines 
The interannual evolution of imported malaria in Spain from the late twentieth century to the twenty-first century shows a clear upward trend (Fig. 3). The linear fit represents a significant ascending line $R^{2}=0.86$ that improves when fitted to the second-degree polynomial line, which explains approximately $90 \%$ of the variance $\left(R^{2}=0.89\right)$.

By extrapolating the second-order linear and polynomial functions, the interval of the cumulative total number of people infected with malaria for the year 2050 was $1100-1800$ people, which is approximately double the number of cases recorded in 2018. Obviously, these are not predictive values, but only an estimation based on the consideration that future trends are similar to the current trends.

Moreover, the impact of the pandemic caused by SARSCoV-2 in 2020 has restricted the population movements in most of the world, so the arrival of people infected with malaria from endemic countries could decrease from 2020 onwards. This circumstance could influence the number of recorded cases of people infected with imported malaria in the same way as the 1918 influenza pandemic coincided with a peak of endemic malaria in Spain, as mentioned in preceding text. It is difficult to analyze the causes of this phenomenon, although it is worth proposing that it could have been influenced by a deterioration in socioeconomic conditions and saturation of the healthcare systems in early-twentieth century Spain. Therefore, it is also relevant to analyze-in the future-whether the COVID-19 pandemic resulted in an increase in the number of cases of autochthonous malaria in countries where malaria is still an endemic disease. This information could help to develop policies for the planning and prevention of infectious epidemics and pandemics, since it would allow for a better understanding of how the impacts of large-scale epidemic processes on national healthcare systems can affect the morbidity of other infectious diseases.

\section{The influence of rurality and urbanization on the spatial distribution of malaria}

In 1949, the distribution of malaria had a clearly rural component (Fig. 4a), with $>94 \%$ of the cases concentrated in municipalities of $\leq 20,000$ inhabitants (Fig. 4b).

The first centralized data on the provincial distribution of people infected with autochthonous malaria in Spain are from 1949. In that year, the distribution of the disease was concentrated in the westernmost provinces of Andalusia (Huelva, Seville, and Cádiz, with 19,018 cases), Extremadura (5322 cases), Castilla-La Mancha (3818 cases), and Murcia (1630 cases) (Fig. 4a). The provinces of the regions of Andalusia, Extremadura, and Murcia alone represented $76.6 \%$ of all recorded cases of autochthonous malaria in that year. This coincides with the main endemic factors of endemic foci of malaria in Spain being associated with other unhealthy water bodies (Western Andalusia and Ciudad Real), poor socioeconomic conditions (Extremadura) (Sousa et al. 2009, 2019), and the presence of a very anthropophilic vector in Murcia (Anopeheles labranchiae), along with Anopheles atroparvus, as in the rest of the country. Unlike An. atroparvus, which is still present in Spain, An. labranchiae disappeared in 1973, although in 1946, it was still abundant, associated with the rice fields of Alicante and Murcia (Blázquez and Zulueta 1980; Eritja et al. 2000; Ramsdale and Snow 2000; Bueno-Marí et al. 2012). Therefore, it would appear that the presence of vectors associated with unhealthy water bodies and poor socioeconomic

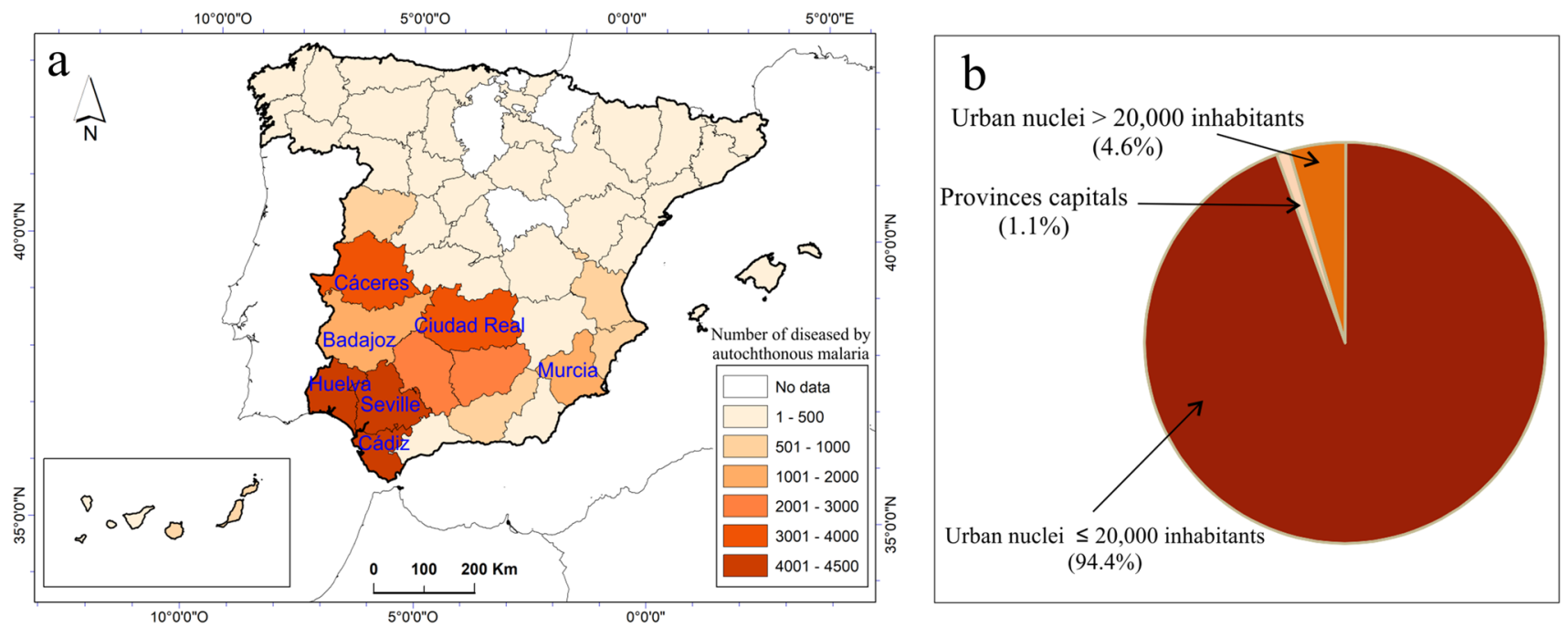

Fig. 4 a Provincial distribution of people infected with autochthonous malaria in Spain in 1949 (modified and expanded from Sousa et al. (2020). b Diagram of sectors showing the distribution of the number of people infected with malaria in Spain during the period of 19551959 , according to the size of the population centers 
conditions have been the main drivers of the main endemic foci of autochthonous malaria in Spain.

During the period of 1955-1959, 94.4\% (Fig. 4b) of the recorded cases of malaria were from population centers of $\leq$ 20,000 inhabitants, and only $4 \%$ were from population centers of $>20,000$ inhabitants (excluding the capitals of each province). As was previously mentioned, in $1900,60 \%$ of the Spanish population worked in the agriculture sector and only $13 \%$ lived in population centers of $>50,000$ inhabitants (Navarro 2002). In this context, although malaria has traditionally been a rural disease, these links are indirect and can be improved by increasing the public investment in health (Noble and Austin 2016). Recent studies in endemic areas of Brazil also show the importance of the urbanization/ rurality gradient for explaining the distribution of the disease (Lana et al. 2017).

On the other hand, imported malaria in Spain in the twenty-first century seems to be associated with those regions with a greater population concentration (e.g., the Community of Madrid, Catalonia, and the Valencian Community; Fig. 5a), although this also appears to be influenced by the proximity to large areas associated with intensive greenhouse agriculture (Fig. 5b).

The cases of imported malaria were concentrated around the main cities and conurbations of Spain. During the period of 2010-2018, most of the cases were concentrated in the regions of Madrid and Catalonia (42\% of all the cases in Spain). This trend remained constant during the second decade of the twenty-first century in all regions. In 2018, 31.6\% (270 cases) and $19.9 \%$ (170 cases) of all reported cases were from Catalonia and Madrid, respectively, followed by Andalusia $(10.4 \%, 89$ cases) and the Valencian Community $(8.7 \%$, 74 cases).

When the distribution of the recorded cases of imported malaria at the regional scale (Fig. 5a) are compared with the provincial population density (Fig. 5b), there is a clear parallelism associated with the most densely populated cities and their conurbations, such as Madrid, Barcelona, Valencia, Seville, Zaragoza, Málaga, Murcia, etc. It is also important to note that these urban nuclei coincide with nodes of communication and are international travel hubs (airports, trains, etc.). In some cases, however, the relationship between recorded cases of imported malaria and population density is not entirely obvious. Therefore, we added the available regional data on intensive greenhouse crops (Fig. 5b), the centers of which are mainly concentrated in some areas of Andalusia, Murcia, the Valencian Community, Catalonia, and Aragon, where the presence of seasonal workers, many of whom come from malaria-endemic countries, could help to explain the concentration of cases in these regions. Future studies, using more disaggregated data of infected people and crops at the provincial or even local scale, could help to better understand the true weight of these agricultural areas and whether they have a significant influence on the seasonal peaks of imported malaria.

To further delve into the drivers that intervene in the prevalence of malaria, we analyzed the role of climatic variables from two different perspectives: variation in the disease at the intraannual and interannual scales, respectively.

\section{Climatic factors related to malaria at the intraannual scale}

To establish measures for the prevention and follow-up of infectious diseases with a seasonal component, such as malaria, it is very useful to know the seasonal variation in the number of infected people and its fluctuations between consecutive years. This information can help to improve the planning and management of available sanitary resources and establish surveillance programs that fit better to those
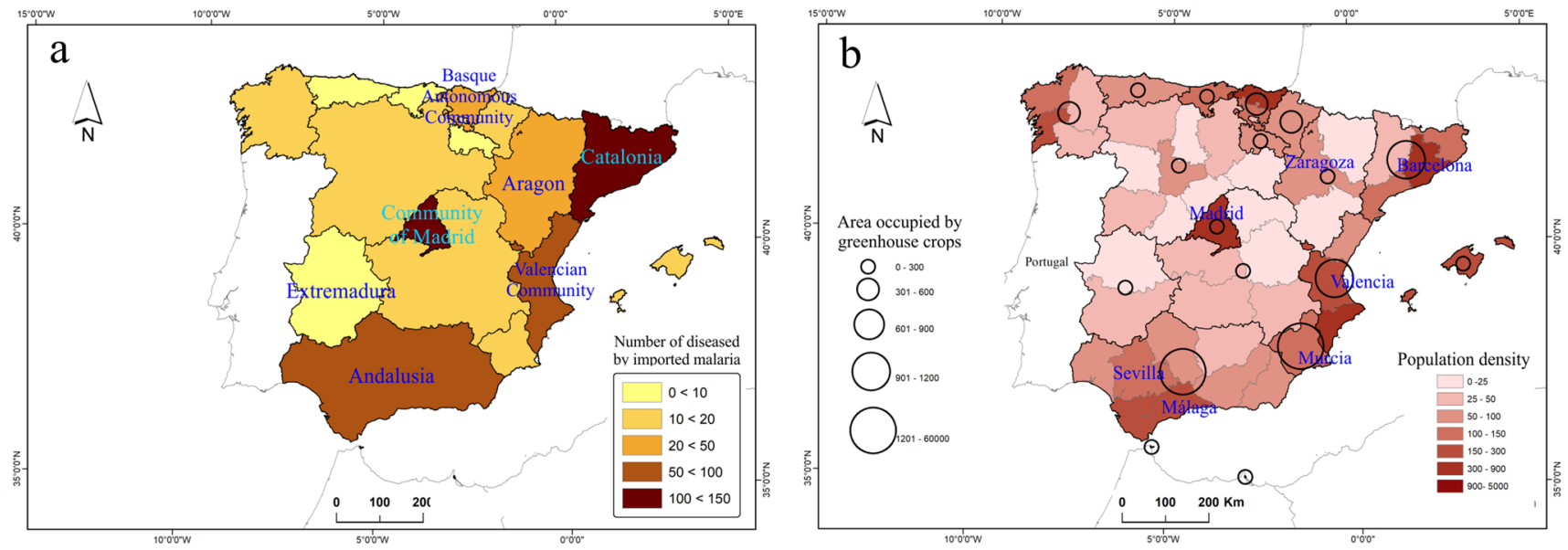

Fig. 5 a Regional distribution of people infected with imported malaria in Spain during the period of 2010-2018. b Provincial distribution of the population density and areas occupied by greenhouse crops in 2019 
seasonal periods associated with a larger number of cases. The evolution of the monthly relative morbidity presents very pronounced seasonal peaks in the case of both autochthonous (Fig. 6a) and imported malaria (Fig. 6b).

Seasonal distribution of autochthonous malaria shows a centered unimodal bell during the summer period (beginning of July), with the tails of the distribution occurring toward the end of spring and beginning of autumn (Fig. 6a). The seasonal distribution of imported malaria also presents a unimodal bell-shaped intraannual distribution, with a maximum value at the beginning of autumn (Fig. 6b), although this distribution is less symmetrical than that of autochthonous malaria. This seasonal distribution of imported malaria indicates an average delay of 2 months with respect to the distribution of autochthonous malaria in Spain. This gap suggests that thermal meteorological variables may play a role as drivers, at least in a coadjuvant manner, only in the case of autochthonous malaria. To corroborate this, we analyzed the relationship between the mean monthly temperatures of these periods and the monthly relative morbidity rate of autochthonous malaria (Fig. 7a) and imported malaria (Fig. 7b).

Figure 7 a shows that there is a clear seasonality in the spread of autochthonous malaria during the summer months $\left(R^{2}=0.88\right)$. When the number of infected people were correlated with the maximum and minimum temperature for the same period, strong correlations were obtained $\left(R^{2}=0.84\right.$ and $R^{2}=0.88$, respectively). However, a different result was obtained for imported malaria (Fig. 7b) since the correlation $\left(R^{2}=0.33\right)$ was much weaker for a similar sample size because of the displacement in the maximum peak of infected people from the summer to the autumn (Fig. 6b).
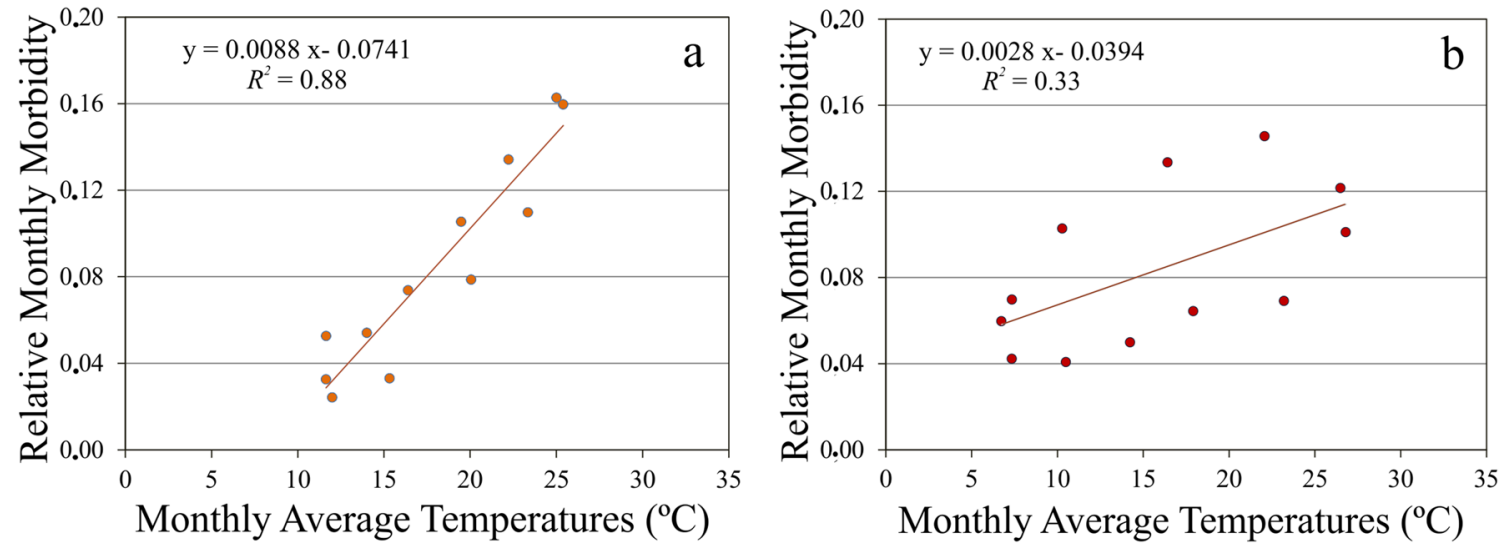

Fig. 6 a Seasonal distribution of autochthonous malaria in Spain during the periods of 1949 and 1954-1956. b Seasonal distribution of imported malaria in Spain during the periods of 2010-2016 and 2018

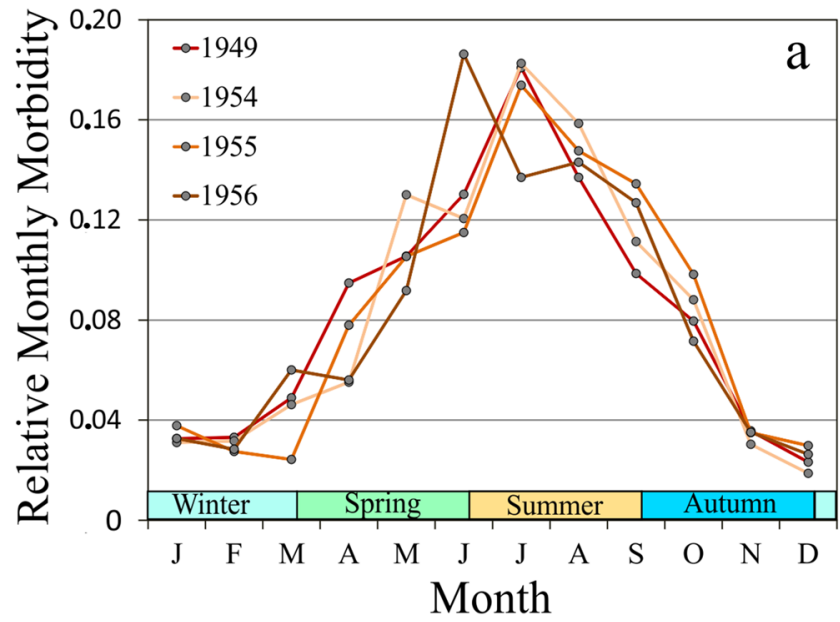

Fig. 7 a Dispersion diagram of the mean monthly temperature in the observatory of Huelva (southwest Spain) and the monthly relative morbidity of autochthonous malaria for the period of 1949-1957 in

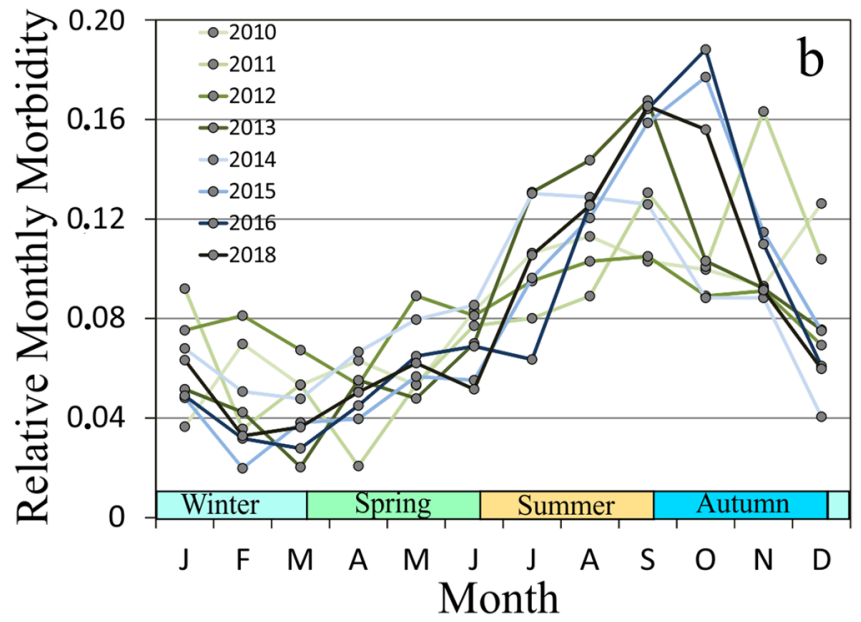

Spain. b Dispersion diagram of the mean monthly temperature in the observatory of Madrid (central Spain) and the monthly relative morbidity of imported malaria for the period of 2010-2018 in Spain 
Since this gap is not directly related to temperature, the graph suggests that other factors not directly linked to climatology could be involved, including the date of displacement of the infected people from the endemic countries to Spain in the post-vacation period (after the summer in the Mediterranean region). Although in the countries of origin the peak of the disease occurs during the warmer months, the displacements due to migration or tourism can take place more frequently during the summer or even later; in such cases, the symptoms could be detected, to a greater extent, at the beginning of autumn.

On the other hand, the correlation obtained for autochthonous malaria (Fig. 7a) is related to the temperature required for the development of both the vector and the parasite that causes the infection. This aspect is relevant for the transmission of malaria, since the average 24-h environmental temperature determines whether the extrinsic life-cycle of the parasite can take place in the anophelines (Petersen et al. 2013). The optimal temperature range for the development of the parasite Plasmodium vivax inside the mosquito is 16-33 ${ }^{\circ} \mathrm{C}$ (Piperaki and Daikos 2016). Above a sustained temperature of $38^{\circ} \mathrm{C}$, there is no transmission of the parasite (Díaz et al. 2005). These temperature requirements explain why the largest mean annual morbidity rates occur in the months that are most favorable to the completion of the corresponding biological cycles (Fig. 6a), with an optimal mean monthly temperature of $20-30{ }^{\circ} \mathrm{C}$ (Fig. 7). The coefficient of determination indicates that, in the annual cycle, almost $90 \%$ of the variability of the morbidity of autochthonous malaria is explained by temperature. This covariation does not necessarily imply causality, although it does indicate that the thermal conditions establish some limits to the optimal development of both the vector and the protozoon that transmits this disease. Therefore, in this case, temperature could act as a rather limiting factor or a factor that, under conditions of the spread of malaria or a malaria epidemic due to other drivers, increases the rate of infected people during an epidemic.

\section{Climatic factors related to malaria at the interannual scale}

If climatic conditions act as a limiting factor or coadjuvate in the expansion of epidemic outbreaks of autochthonous malaria, this must be evident in the historical records of morbidity. Although there are national records of deaths from malaria from 1900 onwards and of people infected with malariae from 1943 onwards, these data cannot be spatially assigned since they refer to the whole of the country. This is a fundamental problem that must be overcome in order to analyze the role of the meteorological variables since Spain is a country characterized by strong variations in temperature and precipitation due to its latitude, longitude and orography.

One alternative is provided by a recent study that shows the possibility of using antimalarial dispensaries to geolocalize the foci of malaria (Sousa et al. 2020). Regarding the period of 1943-1959, for which which data are available on both the total number of infected people and the total number of deaths in the whole country, the coefficient between these two variables is very high $\left(R^{2}=0.95\right)$. The case fatality rate (CFR) for the period of 1943-1954 was $0.34 \%$. Therefore, both variables can be used as a reference for the spread of malaria. According to Navarro (2002), there are only national records on the number of infected people from 1943 onwards, although — separately — we have found records on the number of infected people in the antimalarial dispensaries distributed all over the country for the periods of 1931-1932, 1936-1949, and 1953-1961.

By comparing the data of infected people in the entire country with those recorded in the antimalarial dispensaries for the period with available records (1943-1949 and 1953-1961), we obtained a very good fit $\left(R^{2}=0.998\right)$. Both information sources measured the same parameters with small discrepancies, likely due to administrative causes or the management of data in the antimalarial dispensaries. Since these two variables are closely related, it is possible to use the data on infected people from the antimalarial dispensaries as a tool for studying how the thermal variables affected the evolution of the disease during the period of 1931-1949. The regions that were most affected by autochthonous malaria in Spain during this period were Extremadura, Western Andalusia, and Murcia (see ESM Table S1). During the period of 1931-1949, a mean annual total of 130,752 people infected with malaria were treated in Spain, of whom 90,950 came from the three mentioned regions. Specifically, these three regions accounted for 56.5-93.6\% of the cases of malaria from 1931 to 1949.

As previously described, the intraannual seasonality of the number of infected people appears to be mainly associated with summer (Fig. 6a). Therefore, we selected the precipitation and temperature of summer and spring (Table 2) to analyze its relationship with the number of infected people of each of these historically endemic regions.

In general, the sample size does not allow reliable conclusions to be drawn; in any case, the behavior is not homogeneous in the three regions (see Table 2). Some of these differences are due to these regions being climatically different. In general, the climate of the Atlantic areas (Western Andalusia) is very different from that of the Mediterranean areas (Murcia), with the effect of continentality (in the case of Extremadura) and topography explaining these differences. Nevertheless, climatic factors did not seem to affect the morbidity of autochthonous malaria in Spain. In the specific case of Murcia, Pearson's correlation coefficient 
Table 2 Pearson's correlation coefficient between the number of people infected with autochthonous malaria recorded in the antimalarial dispensaries and the regional meteorological variables for the period of 1931-1949

\begin{tabular}{lcccc}
\hline Region & Spring precipitation & Summer precipitation & Mean spring temperature & $\begin{array}{l}\text { Mean sum- } \\
\text { mer tempera- } \\
\text { ture }\end{array}$ \\
\hline Western Andalusia & 0.258 & 0.145 & 0.072 & 0.325 \\
Extremadura & 0.0001 & 0.182 & -0.018 & 0.281 \\
Murcia & -0.537 & 0.346 & -0.446 & 0.187 \\
\hline
\end{tabular}

No data are available on the number of infected people for the period of 1933-1935)

for spring precipitation $(-0.537)$ is associated with the fact that the period of 1946-1949, when the eradication of the disease began, coincides with very wet years in this region (1946-1949).

Therefore, the results show that there is no clear correlation between the number of infected people in the main endemic regions of Spain and the climatic variables analyzed (Table 2). However, the climatic conditions may intervene as coadjuvants of other drivers of the disease. To analyze this aspect, we compared the quintiles of temperature and precipitation (ESM Table S2) with the number of infected people during the period of 1931-1949 in Western Andalusia, Extremadura and Murcia.

Joint analysis of the results presented in ESM Tables S1 and S2 reveals that, globally, the epidemic periods occurred when there were favorable climatic conditions for the development and transmission of autochthonous malaria. However, when the hygienic/sanitary conditions began to improve, the climatic conditions did not seem to be a relevant barrier to the eradication of the disease. In Western Andalusia, the years of the maximum increase in the number of infected people (1940-1943; see ESM Table S1) coincide with warm and very warm years and include several very wet years (1941-1942; see ESM Table S2). The most interesting aspect is that during the period of 1936-1943, the number of infected people increased progressively, which coincides with all of the years of this period being warm or very warm (in fact, the annual mean temperature and the number of infected people obtained had $R^{2}=0.43$ ). From the year 1944 onwards, the number of infected people decreased in Western Andalusia due to the improvement in economic and sanitary conditions after the Spanish Civil War, despite the fact that the climate was still warm or very warm, although slightly drier.

In the region of Extremadura, the years of maximum increase in the number of infected people (1940-1943; see ESM Table S1) were mostly warm or very warm and, in general, rather wet (see ESM Table S2). From the year 1944 onwards, the number of infected people decreased rapidly due to improvement in the hygienic/sanitary conditions despite corresponding to warm or very warm years. In the region of Murcia, the years of maximum increase in the number of infected people were 1943-1944 (see ESM Table S1). The year 1943 was warm and wet, but 1944 was cold and dry (see ESM Table S2). From 1944 and especially 1945 onwards, the number of infected people decreased substantially due to the fight against malaria, although there is no clear pattern associated with temperature since the climatic conditions were still favorable for the development of the disease.

\section{Conclusions}

During the twentieth century, the main drivers that regulated the morbidity and mortality of autochthonous malaria in Spain were socioeconomic and hygienic and sanitary conditions. However, the endemic foci were strongly associated with the presence of vast areas with unhealthy water bodies (Western Andalusia, Southern Spain, and Ciudad Real), the existence of malaria-transmitting vectors (especially Anopheles labranchiae in the case of Murcia and Alicante), and worse socioeconomic conditions (Northern Extremadura). The outbreak of the epidemic of 1917-1922 was more intense due to overcrowding of the Spanish healthcare system as a consequence of the flu pandemic. In comparison, the outbreak of the epidemic of 1940-1944 was generated by the consequences of the war conflict (movement of troops, deterioration in sanitary conditions, abandonment of the fight against malaria, hunger, scarcity of drugs associated with the international isolation, and the overcrowding of war prisoners and troops).

However the drivers of imported malaria during the twentieth century and, especially during the twenty-first century, seem to be linked to the higher international mobility of the population, especially in association with family visits to endemic countries of Africa (Rey et al. 2010), with some of these countries having strong relations to colonial and/or cultural origins, such as Equatorial Guinea. In the case of imported malaria, the key factor is a close proximity to large cities and suburbs which, in addition, include the main international communication nodes. For this reason, malaria has evolved from a rural disease during the first half of the twentieth century (autochthonous malaria) to an 
urban area-related disease during the twenty-first century (imported malaria). It will not be possible to limit the progressive increase of imported malaria in Spain and other Mediterranean countries as long as it is not possible to eradicate autochthonous malaria in the rest of the world.

The climatic factors did not play a relevant role as drivers of autochthonous malaria in Spain during the twentieth and twenty-first centuries (at least not directly, as is shown by the poor correlation with the thermal variables in the twentyfirst century). However, they have conditioned the disease seasonality. Furthermore, during the epidemic outbreak of 1940-1944, the climatic conditions were optimal for the spread of this outbreak. In this sense, during periods of the twentieth century, the thermal conditions created favorable periods for the spread of autochthonous malaria, thus coadjuvating the spread of the disease. In this context, the results of this study show that the epidemic outbreaks of malaria can be influenced by the local climate. Nevertheless, it is much more complex to establish how epidemic outbreaks of malaria will be affected by climate change in the long term (Patz et al. 2002) since their effects are not always linear and coexist with other non-climatic drivers, which can be more relevant in transmission of the disease.

Determining the historical drivers of malaria can help to provide a better understanding of the risk of the disease and establish future prevention measures. To this end, it would be very interesting to conduct comparative analyses of the seasonality of the disease in countries of the whole Mediterranean region. Although the situation in Europe with respect to the eradication of malaria is very good, the deterioration in healthcare services due to a catastrophe or wars can favor the relapse of malaria (Bruce-Chwatt and De Zulueta 1980; WHO 2006). In the late twentieth century, the local transmission of malaria reestablished in the Caucasus, the republics of Central Asia and, to a lesser extent, the Russian Federation, after the war in Afghanistan and the dissolution of the Soviet Union. In Turkey, a sharp increase in the number of cases of malaria in the 1990s was associated with a large migratory movement of refugees from Iraq during the First Gulf War (WHO 2016; Berglar and Vembar 2019).

Changes in the economic conditions and budget cuts in the national healthcare systems of European countries, such as those associated with the economic crisis of 2008, can also contribute to the relapse of infectious diseases, such as malaria, that had been considered to be eradicated (Andriopoulos et al. 2013; Danis et al 2013; Karanikolos et al. 2013; Smith et al. 2014). One of the lessons from the past is the increase in the number of cases of endemic malaria in Spain during the pandemic flu of 1918. Future studies will have to determine whether the overcrowding of healthcare systems due to the COVID-19 pandemic is a key factor driving the prevalence of malaria in countries where it is still endemic. Some aspects that may have a negative influence on this are:
(1) the fact that both infections share several easily recognizable symptoms (Chanda-Kapata et al. 2020), which may lead to undervaluing the presence of some of these infections (or even co-infections; Ray et al. 2020); (2) the abandonment of antimalarial treatment and follow-ups; and (3) limitations in the supplies of antimalarial drugs (Di Gennaro et al. 2020; Nghochuzie et al. 2020).

Supplementary Information The online version contains supplementary material available at https://doi.org/10.1007/s41207-021-00245-8.

Acknowledgements We want to thank the comments and suggestions of reviewers that have helped us to improve the MS.

\section{Compliance with ethical standards}

Conflict of interest The authors declare no conflict of interest.

\section{References}

Andriopoulos P, Economopoulou A, Spanakos G, Assimakopoulos G (2013) A local outbreak of autochthonous Plasmodium vivax malaria in Laconia, Greece - a re-emerging infection in the southern borders of Europe? Int J Infect Dis 17:e125-e128. https://doi. org/10.1016/j.ijid.2012.09.009

Barona JL, Perdiguero-Gil E (2008) Health and the war. Changing schemes and health conditions during the Spanish civil war. Dynamis 28:103-126. https://doi.org/10.4321/s0211-9536200800 0100005

Basic Surveillance System of the Valencian Community (2020). http:// www.sp.san.gva.es/DgspPortal/docs/epidemiologia/casos_tasas_ anuales.htm. Accessed 7 Apr 2020

Battle KE, Lucas TCD, Nguyen M et al. (2019) Mapping the global endemicity and clinical burden of Plasmodium vivax, 2000-17: a spatial and temporal modelling study. Lancet 394:332-343. https://doi.org/10.1016/S0140-6736(19)31096-7

Berglar AV, Vembar SS (2019) Past, present and future of malaria prevalence and eradication in the light of climate change. In: Elias $\mathrm{S}$ (ed)Reference module in earth systems and environmental sciences. Elsevier, Amsterdam, pp 49-67

Blazquez J, De Zulueta J (1980) The disappearance of Anopheles labranchiae from Spain. Parassitologia 22:161-163

Bruce-Chwatt LJ, Zulueta J (1980) The rise and fall of malaria in Europe: a historico-epidemiological study. Oxford University Press, Oxford

Bueno-Marí R, Bernués-Bañeres A, Jiménez-Peydró R (2012) Updated checklist and distribution maps of mosquitoes (Diptera: Culicidae) of Spain. Eur Mosq Bull 30:91-126. https://www.researchgate. net/profile/Ruben_Bueno_Mari/publication/287181603_Updat ed_checklist_and_distribution_maps_of_mosquitoes_Diptera Culicidae_of_Spain/links/56779b8508ae502c99d3e3a8/Updat ed-checklist-and-distribution-maps-of-mosquitoes-Diptera-Culic idae-of-Spain.pdf

Bulletins of the Carlos III Institute (2020) https://www.isciii.es/QueHa cemos/Servicios/VigilanciaSaludPublicaRENAVE/Enfermedad esTransmisibles/Boletines/Paginas/BoletinSemanalEnRed.aspx. Accessed 7 Apr 2020

Camarillo-Naranjo JM, Álvarez-Francoso JI, Limones-Rodríguez N et al (2019) The global climate monitor system: from climate datahandling to knowledge dissemination. Int J Digit Earth 12:394414. https://doi.org/10.1080/17538947.2018.1429502 
Chanda-Kapata P, Kapata N, Zumla A (2020) COVID-19 and malaria: a symptom screening challenge for malaria endemic countries. Int J Infect Dis 94:151-153. https://doi.org/10.1016/j. ijid.2020.04.007

Chowell G, Erkoreka A, Viboud C, Echeverri-Dávila B (2014) Spatialtemporal excess mortality patterns of the 1918-1919 influenza pandemic in Spain. BMC Infect Dis 14:371. https://doi.org/10. 1186/1471-2334-14-371

Danis K, Lenglet A, Tseroni M et al (2013) Malaria in Greece: historical and current reflections on a re-emerging vector borne disease. Travel Med Infect Dis 11:8-14. https://doi.org/10.1016/j.tmaid. 2013.01.001

Di Gennaro F, Marotta C, Locantore P et al (2020) Malaria and COVID-19: common and different findings. Trop Med Infect Dis 5:141. https://doi.org/10.3390/tropicalmed5030141

Díaz J, Ballester F, López-Vélez R (2005) Impacts on human health. In: Moreno Rodríguez JM (ed) A preliminary general assessment of the impacts in Spain due to the effects of climate change. Ministerio de Medio Ambiente, Madrid, pp 699-741

Eritja R, Aranda C, Padrós J, et al (2000) An annotated checklist and bibliography of the mosquitoes of Spain (Diptera: Culicidae). Eur Mosq Bull 8:10-18. https://www.cabdirect.org/cabdirect/abstract/ 20003035086

Fernández Astasio B (2003) La erradicación del paludismo en España: aspectos biológicos de la lucha antipalúdica. Universidad Complutense de Madrid, Servicio de Publicaciones, Madrid

Goldmeier D, Guallar C (2003) Syphilis: an update. Clin Med (Lond) 3:209-211. https://doi.org/10.7861/clinmedicine.3-3-209

Guerra CA, Snow RW, Hay SI (2006) Mapping the global extent of malaria in 2005. Trends Parasitol 22:353-358. https://doi.org/10. 1016/j.pt.2006.06.006

Gwitira I, Murwira A, Masocha M et al (2019) GIS-based stratification of malaria risk zones for Zimbabwe. Geocarto Int 34:1163-1176. https://doi.org/10.1080/10106049.2018.1478889

Hay SI, Cox J, Rogers DJ et al (2002) Regional warming and malaria resurgence: commentary. Nature 420:628. https://doi.org/10.1038/ $420628 \mathrm{a}$

Herrador Z, Fernández-Martínez B, Quesada-Cubo V et al (2019) Imported cases of malaria in Spain: Observational study using nationally reported statistics and surveillance data, 2002-2015. Malar J 18:230. https://doi.org/10.1186/s12936-019-2863-2

Hertig E (2019) Distribution of Anopheles vectors and potential malaria transmission stability in Europe and the Mediterranean area under future climate change. Parasites Vectors 12:18. https:// doi.org/10.1186/s13071-018-3278-6

Iriso A, Bueno-Marí R, De las Heras E et al (2017) Cambio climático en España y su influencia en las enfermedades de transmisión vectorial. Rev Salud Ambient 17:70-86. https://zaguan.unizar.es/ record/70016/files/texto_completo.pdf

Karanikolos M, Mladovsky P, Cylus J et al (2013) Financial crisis, austerity, and health in Europe. Lancet 381:1323-1331. https:// doi.org/10.1016/S0140-6736(13)60102-6

Lana RM, Riback TIS, Lima TFM et al (2017) Socioeconomic and demographic characterization of an endemic malaria region in Brazil by multiple correspondence analysis. Malar J 16:397. https://doi.org/10.1186/s12936-017-2045-z

López-Vélez R, Molina R (2005) Cambio climático en España y riesgo de enfermedades infecciosas y parasitarias transmitidas por artrópodos y roedores. Rev Esp Salud Publica 79:177-190

Navarro R (2002) Análisis de la sanidad en España a los largo del siglo XX. Instituto de Salud Carlos III (Ministerio de Sanidad), Madrid

Navarro M, Navaza B, Guionnet A, López-Vélez R (2012) Chagas disease in Spain: need for further public health measures. PLoS Negl Trop Dis 6:e1962. https://doi.org/10.1371/journal.pntd.0001962

Nghochuzie NN, Olwal CO, Udoakang AJ et al (2020) Pausing the fight against malaria to combat the COVID-19 pandemic in
Africa: is the future of malaria bleak? Front Microbiol 11:1476. https://doi.org/10.3389/fmicb.2020.01476

Noble MD, Austin KF (2016) Rural disadvantage and malaria in lessdeveloped nations: a cross-national investigation of a neglected disease. Rural Sociol 81:99-134. https://doi.org/10.1111/ruso. 12087

Omumbo JA, Hay SI, Goetz SJ et al (2002) Updating historical maps of malaria transmission intensity in East Africa using remote sensing. Photogramm Eng Remote Sens 68:161-166

Patz JA, Hulmet M, Rosenzweig C et al (2002) Climate change: regional warming and malaria resurgence. Nature 420:627-628. https://doi.org/10.1038/420627a

Petersen E, Severini C, Picot S (2013) Plasmodium vivax malaria: a re-emerging threat for temperate climate zones? Travel Med Infect Dis 11:51-59. https://doi.org/10.1016/j.tmaid.2013.01.003

Piperaki ET, Daikos GL (2016) Malaria in Europe: emerging threat or minor nuisance? Clin Microbiol Infect 22:487-493. https://doi. org/10.1016/j.cmi.2016.04.023

Pletsch D (1965) Informe sobre una misión efectuada en España en septiembre-noviembre de 1963 destinada a la certificación de la erradicación del paludismo. Rev Sanid Hig Publica (Madr) 39:309-367

Ramsdale C, Snow K (2000) Distribution of the genus Anopheles in Europe. Eur Mosq Bull 7:1-26

Raoult D, Woodward T, Dumler JS (2004) The history of epidemic typhus. Infect Dis Clin North Am 18:127-140. https://doi.org/10. 1016/S0891-5520(03)00093-X

Ray M, Vazifdar A, Shivaprakash S (2020) Co-infection with malaria and coronavirus disease-2019. J Glob Infect Dis 12:162. https:// doi.org/10.4103/jgid.jgid_160_20

Rey S, Zuza I, Martínez-Mondéjar B et al (2010) Imported malaria in an area in southern Madrid, 2005-2008. Malar J. https://doi.org/ $10.1186 / 1475-2875-9-290$

Rico-Avelló C (1950) La epidemia de paludismo de la postguerra. Rev Sanid Hig Publica (Madr) 24:701-737. https://pubmed.ncbi.nlm. nih.gov/14816802/

Rodríguez-Ocaña E, Ballester Añón R, Perdiguero Gil E et al (2003) La accion medico-social contra el paludismo en la Espana metropolitana y colonial del siglo XX. Consejo Superior de Investigaciones Científicas, Madrid

Schiewe J (2019) Empirical studies on the visual perception of spatial patterns in choropleth maps. KN J Cartogr Geogr Inf 69:217-228. https://doi.org/10.1007/s42489-019-00026-y

Sipe NG, Dale P (2003) Challenges in using geographic information systems (GIS) to understand and control malaria in Indonesia. Malar J 2:1-8. https://doi.org/10.1186/1475-2875-2-1

Smith KR, Woodward A, Campbell-Lendrum D et al (2014) Human health: impacts, adaptation, and co-benefits. In: Intergovernmental Panel on Climate Change (IPCC) (ed) Climate change 2014 impacts, adaptation and vulnerability: part A: global and sectoral aspects. Cambridge University Press, Cambridge, pp 709-754

Sousa A, Andrade F, Félix A, et al (2009) Historical importance of Wetlands in malaria transmission in southwest of Spain. Limnetica 28:283-300. https://idus.us.es/bitstream/handle/11441/ 34460/Historical\%20importance.pdf?sequence $=4 \&$ isAllowed $=y$

Sousa A, García-Barrón L, Vetter M, Morales J (2014) The historical distribution of main malaria foci in Spain as related to water bodies. Int J Environ Res Public Health 11:7896-7917. https://doi. org/10.3390/ijerph110807896

Sousa A, García-Barrón L, Aguilar-Alba M, Vetter M, Morales J (2019) The importance of wetlands and unhealthy water bodies in the distribution of malaria in Spain. In: Chaminé H, Barbieri M, Kisi O, Chen M, Merkel B (eds) Advances in sustainable and environmental hydrology, hydrogeology, hydrochemistry and water resources. Springer, Cham, pp 77-79. https://doi.org/10. 1007/978-3-030-01572-5_19 
Sousa A, Aguilar-Alba M, Vetter M et al (2020) Spatiotemporal distribution of malaria in Spain in a global change context. Atmosphere 11:346. https://doi.org/10.3390/atmos11040346

Spanish Network of Epidemiological Surveillance (2020) https://publi caciones.isciii.es/unit.jsp?unitId=cne. Accessed 7 Apr 2020

SSIbase (2020) Annual reports of the Spanish Statistical Institute (SSIbase). https://www.ine.es/inebaseweb/libros.do?tntp=25687. Accessed 7 Apr 2020

Tampa M, Sarbu I, Matei C et al (2014) Brief history of syphilis. J Med Life 7:4-10

Trilla A, Trilla G, Daer C (2008) The 1918 "Spanish Flu" in Spain. Clin Infect Dis 47:668-673. https://doi.org/10.1086/590567

Weiss DJ, Lucas TCD, Nguyen M et al (2019) Mapping the global prevalence, incidence, and mortality of Plasmodium falciparum,
2000-17: a spatial and temporal modelling study. Lancet 394:322331. https://doi.org/10.1016/S0140-6736(19)31097-9

WHO (2006) From malaria control to elimination in the WHO European region 2006-2015. World Health Organization Regional Office for Europe, Copenhagen

WHO (2016) History of malaria elimination in the European Region. World Health Organization Regional Office for Europe, Copenhagen

WHO (2019) World malaria report 2019. World Health Organization, Copenhagen

Zhao X, Smith DL, Tatem AJ (2016) Exploring the spatiotemporal drivers of malaria elimination in Europe. Malar J 15:122. https:// doi.org/10.1186/s12936-016-1175-Z 